\title{
A Novel Contractor Selection Technique Using the Extended PROMETHEE II Method
}

\author{
Kuei-Hu Chang $\mathbb{D}^{1,2}$ \\ ${ }^{1}$ Department of Management Sciences, Chinese Military Academy, Kaohsiung 830, Taiwan \\ ${ }^{2}$ Institute of Innovation and Circular Economy, Asia University, Taichung 413, Taiwan \\ Correspondence should be addressed to Kuei-Hu Chang; evenken2002@gmail.com
}

Received 25 September 2021; Revised 26 October 2021; Accepted 1 November 2021; Published 18 November 2021

Academic Editor: Ali Ahmadian

Copyright (c) 2021 Kuei-Hu Chang. This is an open access article distributed under the Creative Commons Attribution License, which permits unrestricted use, distribution, and reproduction in any medium, provided the original work is properly cited.

Selecting suitable contractors directly influences product quality, corporate profits, and even sustainable development. The selection problem of contractors is, therefore, a critical issue for the sustainable development of an enterprise. However, traditional contractor selection techniques are unable to handle information regarding the relative importance of criteria or handle nonexistent or missing data in the assessment process of contractor selection. In order to effectively address this problem, this study proposes a new contractor selection technique that integrates the concept of soft set and the PROMETHEE II method to select suitable contractors. Three numerical examples are applied to prove the correctness and effectiveness of the proposed technique. This study also compares the simulation results achieved using the proposed method with those achieved using the traditional weighted arithmetic averaging method and the data envelopment analysis (DEA) technique. The simulation results show that the proposed method is a more general contractor selection technique for handling incomplete information than the traditional weighted arithmetic averaging method and the DEA method.

\section{Introduction}

Contractor selection includes multiple performance assessment criteria and is a multicriteria decision-making (MCDM) issue. Choosing suitable contractors directly affects the competitive advantage of products and the sustainable development of enterprises. Therefore, contractor selection is a critical issue in the supply chain and has received considerable research attention. Many authors have used different computation methods to address contractor selection problems. For example, San Cristobal [1] combined VlseKriterijumska Optimizacija I Kompromisno Resenje (VIKOR), techniques for order preference by similarity to ideal solution (TOPSIS), and the analytical hierarchy process (AHP) methods for selecting suitable contractors for the "La Braguía" road-building project in Spain. Yang et al. [2] proposed an approach based on data envelopment analysis (DEA) that was applied to support the selection of best value contractors in single-input and multiple-output manners. Akcay et al. [3] used the concept of fuzzy logic to propose a fuzzy decision support model for contractor selection of Turkish construction projects. Hasnain et al. [4] proposed an analytical network process (ANP) based decision support system to solve the most valuable contractor selection problems in road construction projects. Chang [5] integrated the soft set and intuitionistic fuzzy weighted average methods to select the best supplier under an incomplete information environment. Gharedaghi and Omidvari [6] integrated the analytical network processing, decisionmaking trial and evaluation laboratory (DEMATEL), and the grey system theory to select suitable safety contractors for oil and gas industries.

The contractor selection assessment process may encounter instances of missing or nonexistent assessment criteria data. Incomplete attribute value information increases the difficulty of assessing contractors. In order to handle incomplete information, the traditional contractor selection method directly deletes incomplete attribute value information. Deleting information, however, results in a reduction in available information and distorts evaluation 
results. Fortunately, the soft set method is able to handle incomplete assessment criteria information. The soft set method was first proposed by Molodtsov [7] to handle the uncertainty of data or traditional mathematical tools unable to handle fuzzy information in the process of information fusion, and following the development of soft sets, numerous studies used the soft set method to handle different decisionmaking problems [7-20].

Contractors play a key role in successful operations and overall project performance; in addition, choosing the right contractors for a particular project is a major challenge in the supply chain. However, traditional contractor selection methods do not consider information regarding the relative importance of criteria. The preference ranking organization method for enrichment evaluation (PROMETHEE) method is one of the most commonly used techniques to solve MCDM issues. The advantages of the PROMETHEE method are that the relative importance of criteria is considered. PROMETHEE method was first introduced by Brans and Vincke [21], applied as an outranking relation technique between pairs of alternatives to solve MCDM problems. Because the PROMETHEE method's calculation is simple and it is easy to operate, numerous studies have used this method to handle decision-making problems in various fields. For example, Brankovic et al. [22] used PROMETHEE and the simplified elimination and choice translating reality (ELECTRE) approach to determine the criterion weight for selecting optimal alternative hydraulic structure solutions. Tian et al. [23] proposed an improved PROMETHEE II method based on axiomatic fuzzy set theory, which simultaneously considered the subjective preferences of experts and the objective weights of assessment criteria. The improved PROMETHEE II method considers ranking, as well as the degree of credibility of the raw data. The PROMETHEE method has been used in many fields, such as alternative locations for solar power plants [24], the assembly line sequencing problem [25], renewable energy source assessment [26, 27], credit risk assessment [28], electricity distribution utility performance assessment [29], logistics warehouse location selection [30], petrochemical industry [31], occupational health and safety [32], and cybersecurity of Industry 4.0 [33]. However, the typical PROMETHEE method cannot handle the incomplete assessment criteria information.

Recently, Yang et al. [2] introduced a DEA-based approach to support the selection of the best value contractor. However, this approach would cause a high repetition rate problem when DEA values are $100 \%$. Moreover, this approach cannot handle cases when the needed expert data is missing or nonexistent during the information assessment process. In order to effectively resolve the above contractor selection issues, this study proposes a flexible PROMETHEE II method to deal with the contractor selection issue, which simultaneously includes complete and incomplete information. To verify the effectiveness of the proposed flexible PROMETHEE II approach, three contractor selection cases were adopted, and the simulation results were compared with the traditional weighted arithmetic averaging method and the DEA method [2].
The major contributions of this paper include the following advantages: (1) the proposed approach can handle incomplete assessment criteria information; (2) the proposed approach considers the relative importance of criteria; (3) the proposed approach considers the subjective preferences of experts; (4) the traditional weighted arithmetic average approach and DEA method can be viewed as special cases of the proposed approach; and (5) the proposed approach provides a more flexible contractor selection technique to support contractor assessment for selection.

The remainder of this paper is arranged as follows. Section 2 reviews related research on the PROMETHEE II method and soft set method. Section 3 introduces the proposed novel contractor selection approach for solving best-value tendering selection problems. Three contractor selection case projects are adopted, and the comparison with other related methods are discussed in Section 4. Finally, the conclusion is given in Section 5.

\section{Preliminaries}

This section presents some fundamental definitions and concepts related to the PROMETHEE II method and soft set.

2.1. PROMETHEE II Method. Brans and Vincke [21] proposed the PROMETHEE II approach that based on the pairwise comparison of alternatives for each criterion to solve MCDM problems. Two types of information are required for the PROMETHEE II approach: (1) the relative importance of the criteria and (2) decision-maker's preference function for comparing alternative contributions $[34,35]$.

The PROMETHEE II method consists of five steps [36]:

Step 1: normalize the decision matrix

$R_{i j}=\frac{\left[x_{i j}-\min \left(x_{i j}\right)\right]}{\max \left(x_{i j}\right)-\min \left(x_{i j}\right)} \quad(i=1,2, \ldots n ; j=1,2, \ldots, m)$,

where $x_{i j}$ is the performance index of the $i^{\text {th }}$ alternative of the $j^{\text {th }}$ criterion.

For nonbeneficial criteria, equation (1) can be rewritten as follows:

$$
R_{i j}=\frac{\left[\max \left(x_{i j}\right)-x_{i j}\right]}{\max \left(x_{i j}\right)-\min \left(x_{i j}\right)} \quad i=1,2, \ldots n ; j=1,2, \ldots, m .
$$

Step 2: calculate the preference function, $P_{j}(a, b)$ as follows:

$$
\begin{aligned}
& P_{j}(a, b)=0 \text { if } \quad R_{a j} \leq R_{b j}, \\
& P_{j}(a, b)=\left(R_{a j}-R_{b j}\right) \text { if } \quad R_{a j}>R_{b j} .
\end{aligned}
$$

Step 3: calculate the aggregated preference function, $\pi(a, b)$ as follows: 


$$
\pi(a, b)=\sum_{j=1}^{m} w_{j} P_{j}(a, b)
$$

where $w_{j}$ is the weight of the $j^{\text {th }}$ criterion.

Step 4: calculate the entering flow, leaving flow, and net flow for each alternative

$$
\begin{aligned}
\varphi^{-}(a) & =\frac{1}{m-1} \sum_{b=1}^{m} \pi(b, a), \\
\varphi^{+}(a) & =\frac{1}{m-1} \sum_{b=1}^{m} \pi(a, b), \\
\varphi(a) & =\varphi^{+}(a)-\varphi^{-}(a),
\end{aligned}
$$

where $\varphi^{-}(a), \varphi^{+}(a)$, and $\varphi(a)$ represent the entering flow, leaving flow, and net flow for each alternative, respectively.

Step 5: determine the ranking of all the possible alternatives.

All possible alternatives are ranked according to the net flow value $\varphi(a)$, with a higher net flow value $\varphi(a)$ representing a better alternative.

2.2. Soft Set. The soft set method is a novel mathematical method developed by Molodtsov [7] to handle the related issues of uncertain and ambiguous data, and the method is explained as follows: assume $U$ indicates an initial universe and $E$ be the parameters set related to the objects in $U$. The set $P(U)$ be the power set of $U$ and $A \subseteq E$.

Definition 1. [7, 37]: A pair $(F, A)$ is called a soft set (on $U$ ), where $F$ is a mapping given by $F: A \longrightarrow P(U)$.

In other words, the soft set over $U$ is a parameterized family of universe $U$ subsets.

Definition 2. [7, 38]: Both two soft sets $(F, X)$ and $(G, Y)$ are in a common universe $U$, and $(F, X)$ is the soft subset of $(G$, $Y)$, represented as $(F, X) \widetilde{\sim}(G, Y)$, if

(i) $X \subseteq Y$ and

(ii) $\forall e \in X, F(e) \subseteq G(e)$.

Definition 3. [38, 39]: Both two soft sets $(F, X)$ and $(G, Y)$ are in a common universe $U$, where the union of $(F, X)$ and $(G$, $Y)$ is represented as $(H, Z)$, and the following conditions are satisfied:

$$
\text { (i) } Z=X \cup Y \text { and } \begin{cases}F(e), & \text { if } e \in X-Y, \\ G(e), & \text { if } e \in Y-X, . \\ F(e) \cup G(e), & \text { if } e \in X \cap Y .\end{cases}
$$

Definition 4. [38, 39]: Both two soft sets $(F, X)$ and $(G, Y)$ are in a common universe $U$, where the intersection of $(F, X)$ and $(G, Y)$ is represented as $(H, Z)$, and the following conditions are satisfied: (i) $Z=X \cap Y$ and

(ii) $\forall e \in Z, H(e)=F(e)$ or $G(e)$.

\section{The Proposed Novel Contractor Selection Method}

Government procurement in Taiwan involves two principles for contractor selection: the best value bid and the lowest bid. The assessment criteria for the best value bid simultaneously include qualitative and quantitative data and present a complicated MCDM problem. However, the traditional contractor selection approach does not consider the relative importance of criteria or subjective preferences of experts. Moreover, instances may occur in the contractor selection assessment process in which assessment criteria data are missing or nonexistent. This will make the contractor selection evaluation more complicated and difficult. In order to effectively address this problem, this paper proposes a flexible PROMETHEE II method to deal with contractor selection problems, which simultaneously includes complete and incomplete information. This study uses the weighted arithmetic averaging method to fill in incomplete assessment criteria score data. Furthermore, this study applies the PROMETHEE II method to handle information about the relative importance of criteria and subjective preferences of experts. This study integrates the PROMETHEE II method and soft set method to select suitable contractors. The results are more suitably and flexibly reflect the actual situation. The implementation steps of the proposed novel contractor selection approach are as follows (depicted in Figure 1):

Step 1: confirm the bidding document assessment criteria.

Determine the content of assessment criteria according to the requirements of the actual bidding documents. Step 2: determine the relative weights of the assessment criteria.

etermine the relative weights of the assessment criteria according to the importance level of the assessment criteria.

Step 3: determine the scores of the assessment criteria for each bidder.

Each committee member determines the assessment criteria scores for each bidder.

Step 4: fill in incomplete assessment criteria score data. If the assessment criteria scores are incomplete, use the weighted arithmetic average approach to fill in incomplete assessment criteria score data.

Step 5: normalize the decision matrix.

Use equations (1) and (2) to compute the normalized decision matrix.

Step 6: compute the preference function $P_{j}(a, b)$.

Use equations (3) and (4) to compute the preference function $P_{j}(a, b)$. 


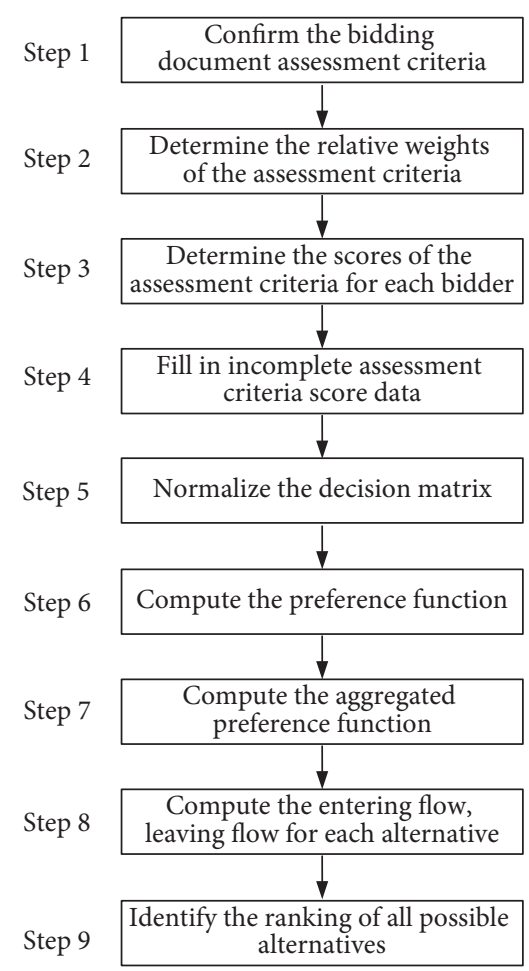

FIGURE 1: Flowchart of the proposed novel contractor selection method.

Step 7: compute the aggregated preference function $\pi(a, b)$.

Use equation (5) to compute the aggregated preference function $\pi(a, b)$.

Step 8: compute the entering flow and leaving flow for each alternative.

Use equations (6)-(7) to compute the entering flow and leaving flow for each alternative.

Step 9: identify the ranking of all possible alternatives.

Use equation (8) to compute the net flow values for each alternative. Rank the net flow $\varphi(a)$ from highest to lowest, with a higher net flow value $\varphi(a)$ representing a better bidder.

\section{Illustrative Example}

4.1. Case Project 1. This section presents an illustrative example of software supplier selection adapted from Yang et al. [2] who proved the effectiveness of the proposed novel contractor selection approach. The case company must select the optimal software supplier in order to develop and plan the management information system. There were six bidders, and a bid opening committee that consisted of four committee members in this software supplier case. The assessment criteria included the comprehension degree for the project $(\mathrm{C} 1)$, system design and planning $(\mathrm{C} 2)$, coding ability of a system (C3), management ability of project (C4), and past achievements and experience (C5). The relative weights of the five evaluation criteria were $0.10,0.30,0.30$, 0.20 , and 0.10 , respectively. The five evaluation criteria were then used by the final bid opening committee to determine the most suitable software supplier. The five assessment criteria scores for each bidder are listed in Table 1.

4.1.1. Solution by the Traditional Weighted Arithmetic Averaging Approach. The traditional weighted arithmetic averaging approach is one of the simplest and most commonly used aggregation operators, and it can be explained as follows.

Definition 5. [40, 41]: A weighted arithmetic averaging (WAA) operator of dimension $n$ is a mapping $F: R^{n} \longrightarrow R$ with associated weight vector $W=\left(w_{1}, w_{2}, \ldots, w_{n}\right)$ and $\sum_{i=1}^{n} w_{i}=1, w_{i} \in[0,1]$ as follows:

$$
W W A\left(a_{1}, a_{2}, \ldots, a_{n}\right)=\sum_{i=1}^{n} w_{i} a_{i}
$$

where $a_{i}$ is the argument variable.

According to the results of Table 1, equation (9) was used to calculate the bidder scores for software supplier selection, as shown in Table 2.

4.1.2. Solution by the DEA Method. Yang et al. [2] proposed a DEA model with single input and multiple outputs to solve the best-value contractor selection problem. They used the decision-making unit (DMU) as a bidder, and the DEA input values were equal to 1 . According to Table 1 , the DEAP software was used to run the DEA CCR model, and the software supplier evaluation results as listed in Table 3, where a bidder's DEA value of $100 \%$ indicates that the bidder has the highest comparative efficiency.

4.1.3. Solution by the Proposed Novel Contractor Selection Approach. The proposed novel contractor selection approach integrates the PROMETHEE II method and the soft set approach to select suitable contractors. In the software supplier selection example, the five assessment criteria scores for six bidders in the final bid opening committee are as listed in Table 1 (Steps $1 \sim 4$ ). The following procedure describes the remaining steps of the proposed method:

Step 5: normalize the decision matrix.

According to Table 1, equations (1) and (2) were used to calculate the normalized decision matrix for different software suppliers, as listed in Table 4.

Step 6: compute the preference function $P_{j}(a, b)$.

Step 7: compute the aggregated preference function $\pi(a, b)$.

According to Table 4, equations (3)-(5) were used to compute the preference function $\left(P_{j}(a, b)\right)$ and aggregated preference function $(\pi(a, b))$ for different software suppliers, as listed in Table 5.

Step 8: compute the entering flow and leaving flow for each alternative.

According to Table 5, equations (6) and (7) were used to calculate the entering and leaving flows for different software suppliers, as shown in Table 6. 
TABLE 1: Actual evaluation data of software supplier.

\begin{tabular}{lccccc}
\hline \multirow{2}{*}{ Bidder } & \multicolumn{5}{c}{ Criteria } \\
& C1 & C2 & C3 & C4 & C5 \\
\hline Bidder 1 & 6.2 & 23.8 & 23.1 & 15.6 & 7.2 \\
Bidder 2 & 6.0 & 23.0 & 23.0 & 15.0 & 6.3 \\
Bidder 3 & 8.0 & 26.3 & 26.3 & 17.5 & 8.5 \\
Bidder 4 & 6.7 & 21.5 & 22.3 & 14.8 & 6.0 \\
Bidder 5 & 8.8 & 26.0 & 27.0 & 17.0 & 8.5 \\
Bidder 6 & 8.2 & 24.5 & 26.3 & 16.7 & 8.0 \\
\hline
\end{tabular}

TABle 2: Software supplier selection by the traditional weighted arithmetic averaging method.

\begin{tabular}{lccccccc}
\hline \multirow{2}{*}{ Bidder } & \multicolumn{6}{c}{ Criteria } & \multirow{2}{*}{ Total score } \\
& C1 & C2 & C3 & C4 & C5 & & \\
\hline Bidder 1 & 6.2 & 23.8 & 23.1 & 15.6 & 7.2 & 75.9 & \\
Bidder 2 & 6.0 & 23.0 & 23.0 & 15.0 & 6.3 & 73.3 & \\
Bidder 3 & 8.0 & 26.3 & 26.3 & 17.5 & 8.5 & 87.6 & Yes \\
Bidder 4 & 6.7 & 21.5 & 22.3 & 14.8 & 6.0 & 71.3 & \\
Bidder 5 & 8.8 & 26.0 & 27.0 & 17.0 & 8.5 & 87.0 & \\
Bidder 6 & 8.2 & 24.5 & 26.3 & 16.7 & 8.0 & 84.7 & \\
\hline
\end{tabular}

Step 9: determine the ranking of all possible alternatives.

According to Table 6, equation (8) was used to calculate the net flow for different software suppliers. The net flow values $\varphi(a)$ was ranked from highest to lowest, with a higher net flow value $\varphi(a)$ representing a better software supplier, as listed in Table 7.

4.1.4. Summary. Case Project 1 involves selecting a software supplier to develop a management information system for the case company. The input data for each bidder was listed in Table 1. Table 8 lists the different calculation results of the traditional weighted arithmetic averaging method, the DEA method, and the proposed method for Case Project 1.

From Table 8, the DEA values for bidders 3 and 5 were $100 \%$. The proposed extended PROMETHEE II method can solve this problem of duplicate DEA value. In the proposed method, the net outranking flow of bidders 3 and 5 were 0.490 and 0.511 , respectively. Therefore, the proposed method can better sort bidder scores.

4.2. Case Project 2. Case Project 2 involves the selection of two security companies to provide security services for a science park [2]. There were seven bidders competing for two awards in this case. The assessment criteria included company organization (C1), planning feasibility (C2), professional capability (C3), price (C4), and presentation and question response (C5). The relative weights for the five assessment criteria were $0.20,0.25,0.25,0.20$, and 0.10 , respectively, and the final evaluation committee selected the best two security services companies based on the five assessment criteria. The five assessment criteria scores for each security services company are listed in Table 9.
4.2.1. Solution by the Traditional Weighted Arithmetic Average Approach. Based on the results of Table 9, equation (9) was used to calculate the bidder scores for security services company selection, as shown in Table 10.

4.2.2. Solution by the DEA Method. According to the data in Table 9, the DEAP software was used to run the DEA CCR model. The security services company selection evaluation results are listed in Table 11. In Table 11, a bidder's DEA value of $100 \%$ indicates that the bidder's performance is the highest.

4.2.3. Solution by the Proposed Method. According to the results of Table 9, equations (1) and (2) were used to calculate the normalized decision matrix of different security companies, as listed in Table 12.

According to the results of Table 12, equations (3)-(5) were used to calculate the preference function $P_{j}(a, b)$ and aggregated preference function for different security companies, as shown in Table 13.

According to the results of Table 13, equations (6)-(8) were used to calculate the entering flow, leaving flow, and net outranking flow for different security companies, as listed in Table 14 .

4.2.4. Summary. Case Project 2 involved the selection of two security companies to provide security for a science park in Taiwan. Table 15 displays the calculation results of the traditional weighted arithmetic averaging method, the DEA method, and the proposed method for Case Project 2.

In Table 15, the traditional weighted arithmetic averaging method identifies bidders 1 and 6 as having the two highest scores, thus the winning bidders. However, the traditional weighted arithmetic averaging method does not consider the relative importance of the criteria or subjective preferences of the experts, which will result in an incorrect conclusion. From Table 15, the DEA values for bidders 1, 2, 3 , 6, and 7 are $100 \%$. The DEA method thus has a high duplicate rate problem. The proposed extended PROMETHEE II method simultaneously considers the objective weights of the assessment criteria and the subjective preferences of the experts. Thus, the proposed method identifies the top two net outranking flows as 0.279 (bidder 1) and 0.212 (bidder 2), which are the winning bids. Therefore, the proposed extended PROMETHEE II approach is more suitable for solving the contractor selection problem.

4.3. Case Project 3. Case Project 3 involved the selection of the best contractor for a local Koji pottery industry promotion company in Chiayi, Taiwan [42]. In this local Koji pottery industry promotion case, there were three bidders, and the final evaluation committee consisted of four committee members. The assessment criteria included the content of service proposal (C1), service management and control of the project (C2), bidder's bid price and components (C3), project ideas and feedback (C4), and brief and responsive (C5). The relative weights for the five assessment 
TABLE 3: Software supplier DEA evaluation results.

\begin{tabular}{lcccccccc}
\hline DMU & Output 1 & Output 2 & Output 3 & Output 4 & Output 5 & Input & DEA value (\%) & Actual winner \\
\hline DMU 1 & 6.2 & 23.8 & 23.1 & 15.6 & 7.2 & 1.0 & 90.5 & 87.5 \\
DMU 2 & 6.0 & 23.0 & 23.0 & 15.0 & 6.3 & 1.0 & 1.0 & 100.0 \\
DMU 3 & 8.0 & 26.3 & 26.3 & 17.5 & 8.5 & 6.0 & Yes \\
DMU 4 & 6.7 & 21.5 & 22.3 & 14.8 & 6.0 & 1.0 & 1.0 & Yes \\
DMU 6 & 8.8 & 26.0 & 27.0 & 17.0 & 8.5 & 1.0 & 97.8 \\
DMU 6 & 8.2 & 24.5 & 26.3 & 16.7 & 8.0 & 1.0 & \\
\hline
\end{tabular}

TABle 4: Normalized the decision matrix for different software suppliers.

\begin{tabular}{lccccc}
\hline \multirow{2}{*}{ Bidder } & \multicolumn{5}{c}{ Criteria } \\
& C1 & C2 & C3 & C4 & C5 \\
\hline Bidder 1 & 0.071 & 0.479 & 0.170 & 0.296 & 0.480 \\
Bidder 2 & 0.000 & 0.313 & 0.149 & 0.074 & 0.120 \\
Bidder 3 & 0.714 & 1.000 & 0.851 & 1.000 & 1.000 \\
Bidder 4 & 0.250 & 0.000 & 0.000 & 0.000 & 0.000 \\
Bidder 5 & 1.000 & 0.938 & 1.000 & 0.815 & 1.000 \\
Bidder 6 & 0.786 & 0.625 & 0.851 & 0.704 & 0.800 \\
\hline
\end{tabular}

TABLE 5: Aggregated preference function for different software suppliers.

\begin{tabular}{lcccccc}
\hline Bidder & Bidder & Bidder & Bidder & Bidder & Bidder & Bidder \\
& 1 & 2 & 3 & 4 & 5 & 6 \\
\hline Bidder 1 & - & 0.144 & 0.000 & 0.302 & 0.000 & 0.000 \\
Bidder 2 & 0.000 & - & 0.000 & 0.165 & 0.000 & 0.000 \\
Bidder 3 & 0.618 & 0.762 & - & 0.902 & 0.056 & 0.192 \\
Bidder 4 & 0.018 & 0.025 & 0.000 & - & 0.000 & 0.000 \\
Bidder 5 & 0.635 & 0.779 & 0.073 & 0.919 & - & 0.202 \\
Bidder 6 & 0.433 & 0.577 & 0.007 & 0.717 & 0.000 & - \\
\hline
\end{tabular}

criteria were $0.30,0.25,0.15,0.20$, and 0.10 , respectively. Performance evaluation scores of each bidder are listed in Table 16.

4.3.1. Solution by the Traditional Weighted Arithmetic Average Approach. Some information provided by Expert P3 were missing or nonexistent data, and thus, only information provided by Experts P1, P2, and P4 were considered. According to the results of Table 16, equation (9) was used to calculate the bidder scores for local Koji pottery industry promotion contractor selection, as shown in Table 17.

4.3.2. Solution by the DEA Method. From Table 16, Experts $\mathrm{P} 1, \mathrm{P} 2$, and $\mathrm{P} 4$ provided complete evaluation information, while Expert P3's evaluation information was incomplete. The DEA method can only work with complete expert information. Therefore, only the information provided by Experts P1, P2, and P4 were considered. According to Table 16, the DEAP software was used to run the DEA CCR model, and the local Koji pottery industry promotion company selection evaluation result is shown in Table 18.
TABLE 6: Entering and leaving flows for different software suppliers.

\begin{tabular}{lcc}
\hline Bidder & Entering flow & Leaving flow \\
\hline Bidder 1 & 0.341 & 0.089 \\
Bidder 2 & 0.457 & 0.033 \\
Bidder 3 & 0.016 & 0.506 \\
Bidder 4 & 0.601 & 0.009 \\
Bidder 5 & 0.011 & 0.522 \\
Bidder 6 & 0.079 & 0.347 \\
\hline
\end{tabular}

TAвLE 7: Net outranking flow values for different alternative software suppliers.

\begin{tabular}{lcc}
\hline Bidder & Net outranking flow & Rank \\
\hline Bidder 1 & -0.251 & 4 \\
Bidder 2 & -0.424 & 5 \\
Bidder 3 & 0.490 & 2 \\
Bidder 4 & -0.593 & 6 \\
Bidder 5 & 0.511 & 1 \\
Bidder 6 & 0.268 & 3 \\
\hline
\end{tabular}

4.3.3. Solution by the Proposed Method. The proposed novel contractor selection technique is not only able to handle the objective weights of assessment criteria and subjective preferences of experts but can also handle missing or nonexistent contractor selection assessment process data by using the average value of the complete information to complete the information. According to Table 16, equations (1) and (2) were used to compute normalized decision matrix for the local Koji pottery industry promotion companies, as listed in Table 19.

According to Table 19, quations (3)-(5) were used to calculate the preference function $P_{j}(a, b)$ and aggregated preference function for different local Koji pottery industry promotion companies, as shown in Table 20.

According to Table 20, equations (6)-(8) were used to calculate the entering flow, leaving flow, and net outranking flow of different local Koji pottery industry promotion companies, as shown in Table 21.

4.3.4. Summary. Case Project 3 involved the selection of the best bidder as a local Koji pottery industry promotion company in Taiwan. Table 22 shows the calculation results of the traditional weighted arithmetic averaging method, the DEA method, and the proposed method for Case Project 3. 
TABLe 8: Results of different calculation methods for Case Project 1.

\begin{tabular}{|c|c|c|c|c|c|c|}
\hline \multirow{2}{*}{ Bidder } & \multicolumn{2}{|c|}{$\begin{array}{c}\text { Traditional weighted } \\
\text { arithmetic averaging method }\end{array}$} & \multicolumn{2}{|c|}{ DEA method } & \multicolumn{2}{|c|}{ The proposed method } \\
\hline & Total score & Ranking & DEA value (\%) & Ranking & Net outranking flow & Ranking \\
\hline Bidder 1 & 75.9 & 4 & 90.5 & 4 & -0.251 & 4 \\
\hline Bidder 2 & 73.3 & 5 & 87.5 & 5 & -0.424 & 5 \\
\hline Bidder 3 & 87.6 & 1 & 100.0 & 1 & 0.490 & 2 \\
\hline Bidder 4 & 71.3 & 6 & 84.7 & 6 & -0.593 & 6 \\
\hline Bidder 5 & 87.0 & 2 & 100.0 & 1 & 0.511 & 1 \\
\hline Bidder 6 & 84.7 & 3 & 97.8 & 3 & 0.268 & 3 \\
\hline
\end{tabular}

TABLE 9: Actual evaluation data of security services companies.

\begin{tabular}{|c|c|c|c|c|c|}
\hline \multirow{2}{*}{ Bidder } & \multicolumn{5}{|c|}{ Criteria } \\
\hline & $\mathrm{C} 1$ & $\mathrm{C} 2$ & $\mathrm{C} 3$ & $\mathrm{C} 4$ & $\mathrm{C} 5$ \\
\hline Bidder 1 & 18.0 & 20.5 & 20.2 & 17.5 & 7.8 \\
\hline Bidder 2 & 13.0 & 22.0 & 21.0 & 17.0 & 8.0 \\
\hline Bidder 3 & 18.3 & 19.7 & 18.8 & 16.8 & 7.8 \\
\hline Bidder 4 & 12.5 & 18.5 & 17.3 & 17.2 & 7.2 \\
\hline Bidder 5 & 12.7 & 21.3 & 20.1 & 16.1 & 7.7 \\
\hline Bidder 6 & 17.4 & 20.1 & 19.1 & 17.0 & 8.0 \\
\hline Bidder 7 & 16.9 & 19.9 & 18.9 & 17.0 & 8.0 \\
\hline
\end{tabular}

TABLE 10: Security services company selection by the traditional weighted arithmetic average approach.

\begin{tabular}{|c|c|c|c|c|c|c|c|}
\hline \multirow{2}{*}{ Bidder } & \multicolumn{5}{|c|}{ Criteria } & \multirow{2}{*}{ Total score } & \multirow{2}{*}{ Actual winner } \\
\hline & $\mathrm{C} 1$ & $\mathrm{C} 2$ & $\mathrm{C} 3$ & $\mathrm{C} 4$ & $\mathrm{C} 5$ & & \\
\hline Bidder 1 & 18.0 & 20.5 & 20.2 & 17.5 & 7.8 & 84.0 & Yes \\
\hline Bidder 2 & 13.0 & 22.0 & 21.0 & 17.0 & 8.0 & 81.0 & \\
\hline Bidder 3 & 18.3 & 19.7 & 18.8 & 16.8 & 7.8 & 81.5 & \\
\hline Bidder 4 & 12.5 & 18.5 & 17.3 & 17.2 & 7.2 & 72.7 & \\
\hline Bidder 5 & 12.7 & 21.3 & 20.1 & 16.1 & 7.7 & 78.0 & \\
\hline Bidder 6 & 17.4 & 20.1 & 19.1 & 17.0 & 8.0 & 81.7 & Yes \\
\hline Bidder 7 & 16.9 & 19.9 & 18.9 & 17.0 & 8.0 & 80.6 & \\
\hline
\end{tabular}

TABLE 11: Security services company DEA evaluation results.

\begin{tabular}{lcccccccc}
\hline DMU & Output 1 & Output 2 & Output 3 & Output 4 & Output 5 & Input & DEA value (\%) & Actual winner \\
\hline DMU 1 & 18.0 & 20.5 & 20.2 & 17.5 & 7.8 & 1.0 & 100.0 & Yes \\
DMU 2 & 13.0 & 22.0 & 21.0 & 17.0 & 8.0 & 1.0 & 100.0 & Yes \\
DMU 3 & 18.3 & 19.7 & 18.8 & 16.8 & 7.8 & 1.0 & 100.0 & Yes \\
DMU 4 & 12.5 & 18.5 & 17.3 & 17.2 & 7.2 & 1.0 & 98.3 & 96.9 \\
DMU 5 & 12.7 & 21.3 & 20.1 & 16.1 & 7.7 & 1.0 & 100.0 & Yes \\
DMU 6 & 17.4 & 20.1 & 19.1 & 17.0 & 8.0 & 1.0 & 100.0 & Yes \\
DMU 7 & 16.9 & 19.9 & 18.9 & 17.0 & 8.0 & 1.0 & & \\
\hline
\end{tabular}

TABLe 12: Normalized the decision matrix of different security companies.

\begin{tabular}{|c|c|c|c|c|c|}
\hline \multirow{2}{*}{ Bidder } & \multicolumn{5}{|c|}{ Criteria } \\
\hline & $\mathrm{C} 1$ & $\mathrm{C} 2$ & C3 & $\mathrm{C} 4$ & C5 \\
\hline Bidder 1 & 0.948 & 0.571 & 0.784 & 1.000 & 0.750 \\
\hline Bidder 2 & 0.086 & 1.000 & 1.000 & 0.643 & 1.000 \\
\hline Bidder 3 & 1.000 & 0.343 & 0.405 & 0.500 & 0.750 \\
\hline Bidder 4 & 0.000 & 0.000 & 0.000 & 0.786 & 0.000 \\
\hline Bidder 5 & 0.034 & 0.800 & 0.757 & 0.000 & 0.625 \\
\hline Bidder 6 & 0.845 & 0.457 & 0.486 & 0.643 & 1.000 \\
\hline Bidder 7 & 0.759 & 0.400 & 0.432 & 0.643 & 1.000 \\
\hline
\end{tabular}


TABLE 13: Aggregated preference function of different security companies.

\begin{tabular}{lccccccc}
\hline Bidder & Bidder 1 & Bidder 2 & Bidder 3 & Bidder 4 & Bidder 5 & Bidder 6 & Bidder 7 \\
\hline Bidder 1 & - & 0.244 & 0.252 & 0.646 & 0.402 & 0.195 \\
Bidder 2 & 0.186 & - & 0.367 & 0.617 & 0.287 & 0.264 \\
Bidder 3 & 0.010 & 0.183 & - & 0.462 & 0.306 & 0.031 \\
Bidder 4 & 0.000 & 0.029 & 0.057 & - & 0.157 & 0.029 \\
Bidder 5 & 0.057 & 0.000 & 0.202 & 0.459 & - & 0.153 \\
Bidder 6 & 0.025 & 0.152 & 0.102 & 0.505 & 0.328 & 0.029 \\
Bidder 7 & 0.025 & 0.134 & 0.075 & 0.460 & 0.311 & 0.000 \\
\hline
\end{tabular}

TABLE 14: Entering, leaving, and net flows for different security companies.

\begin{tabular}{lccc}
\hline Bidder & Entering flow & Leaving flow & Net outranking flow \\
\hline Bidder 1 & 0.051 & 0.330 & 0.279 \\
Bidder 2 & 0.124 & 0.336 & 0.212 \\
Bidder 3 & 0.176 & 0.173 & -0.002 \\
Bidder 4 & 0.525 & 0.050 & -0.475 \\
Bidder 5 & 0.299 & 0.175 & -0.123 \\
Bidder 6 & 0.112 & 0.193 & 0.081 \\
Bidder 7 & 0.139 & 0.167 & 0.028 \\
\hline
\end{tabular}

Table 15: Results of different calculation methods for Case Project 2.

\begin{tabular}{|c|c|c|c|c|c|c|}
\hline \multirow[t]{2}{*}{ Bidder } & \multicolumn{2}{|c|}{$\begin{array}{c}\text { Traditional weighted } \\
\text { arithmetic averaging method }\end{array}$} & \multicolumn{2}{|c|}{ DEA method } & \multicolumn{2}{|c|}{ The proposed method } \\
\hline & Total score & Ranking & DEA value (\%) & Ranking & Net outranking flow & Ranking \\
\hline Bidder 1 & 84.0 & 1 & 100.0 & 1 & 0.279 & 1 \\
\hline Bidder 2 & 81.0 & 4 & 100.0 & 1 & 0.212 & 2 \\
\hline Bidder 3 & 81.5 & 3 & 100.0 & 1 & -0.002 & 5 \\
\hline Bidder 4 & 72.7 & 7 & 98.3 & 6 & -0.475 & 7 \\
\hline Bidder 5 & 78.0 & 6 & 96.9 & 7 & -0.123 & 6 \\
\hline Bidder 6 & 81.7 & 2 & 100.0 & 1 & 0.081 & 3 \\
\hline Bidder 7 & 80.6 & 5 & 100.0 & 1 & 0.028 & 4 \\
\hline
\end{tabular}

TABLE 16: Performance evaluation scores of local Koji pottery industry promotion contractors.

\begin{tabular}{|c|c|c|c|c|c|}
\hline Criterion & Weighting (\%) & Expert & Bidder 1 & Bidder 2 & Bidder 3 \\
\hline \multirow{4}{*}{$\mathrm{C} 1$} & \multirow{4}{*}{30} & P1 & 25 & 24 & 25 \\
\hline & & $\mathrm{P} 2$ & 24 & 25 & 25 \\
\hline & & P3 & 24 & 23 & 24 \\
\hline & & $\mathrm{P} 4$ & 24 & 25 & 24 \\
\hline \multirow{4}{*}{$\mathrm{C} 2$} & \multirow{4}{*}{25} & P1 & 23 & 23 & 22 \\
\hline & & $\mathrm{P} 2$ & 22 & 22 & 21 \\
\hline & & P3 & $*$ & $*$ & $*$ \\
\hline & & $\mathrm{P} 4$ & 21 & 20 & 21 \\
\hline \multirow{4}{*}{$\mathrm{C} 3$} & \multirow{4}{*}{15} & P1 & 11 & 13 & 12 \\
\hline & & $\mathrm{P} 2$ & 11 & 12 & 12 \\
\hline & & P3 & 12 & 13 & 12 \\
\hline & & $\mathrm{P} 4$ & 12 & 13 & 12 \\
\hline \multirow{4}{*}{$\mathrm{C} 4$} & \multirow{4}{*}{20} & P1 & 17 & 18 & 17 \\
\hline & & $\mathrm{P} 2$ & 16 & 16 & 17 \\
\hline & & P3 & 15 & 16 & 18 \\
\hline & & P4 & 15 & 17 & 17 \\
\hline \multirow{4}{*}{ C5 } & \multirow{4}{*}{10} & P1 & 8 & 7 & 8 \\
\hline & & $\mathrm{P} 2$ & 6 & 6 & 7 \\
\hline & & P3 & 7 & 7 & 8 \\
\hline & & $\mathrm{P} 4$ & 8 & 7 & 7 \\
\hline
\end{tabular}

*indicates missing or nonexistent data. 
TABLE 17: Local Koji pottery industry promotion contractor selection by the traditional weighted arithmetic averaging method.

\begin{tabular}{|c|c|c|c|c|c|c|c|c|}
\hline \multirow{2}{*}{ Bidder } & \multirow{2}{*}{ Expert } & \multicolumn{5}{|c|}{ Criteria } & \multirow{2}{*}{ Total score } & \multirow{2}{*}{ Actual winner } \\
\hline & & $\mathrm{C} 1$ & $\mathrm{C} 2$ & $\mathrm{C} 3$ & $\mathrm{C} 4$ & $\mathrm{C} 5$ & & \\
\hline \multirow{3}{*}{ Bidder 1} & P1 & 25 & 23 & 11 & 17 & 8 & 81.0 & \\
\hline & $\mathrm{P} 2$ & 24 & 22 & 11 & 16 & 6 & & \\
\hline & $\mathrm{P} 4$ & 24 & 21 & 12 & 15 & 8 & & \\
\hline \multirow{3}{*}{ Bidder 2} & $\mathrm{P} 1$ & 24 & 23 & 13 & 18 & 7 & 82.7 & Yes \\
\hline & $\mathrm{P} 2$ & 25 & 22 & 12 & 16 & 6 & & \\
\hline & $\mathrm{P} 4$ & 25 & 20 & 13 & 17 & 7 & & \\
\hline \multirow{3}{*}{ Bidder 3} & $\mathrm{P} 1$ & 25 & 22 & 12 & 17 & 8 & 82.3 & \\
\hline & $\mathrm{P} 2$ & 25 & 21 & 12 & 17 & 7 & & \\
\hline & $\mathrm{P} 4$ & 24 & 21 & 12 & 17 & 7 & & \\
\hline
\end{tabular}

TABLE 18: DEA local Koji pottery industry promotion contractor evaluation result.

\begin{tabular}{lcccccccc}
\hline Bidder & Output 1 & Output 2 & Output 3 & Output 4 & Output 5 & Input & DEA value (\%) & Actual winner \\
\hline Bidder 1 & 24.3 & 22.0 & 11.3 & 16.0 & 7.3 & 1.0 & 100.0 & Yes \\
Bidder 2 & 24.7 & 21.7 & 12.7 & 17.0 & 6.7 & 1.0 & 100.0 & Yes \\
Bidder 3 & 24.7 & 21.3 & 12.0 & 17.0 & 7.3 & 1.0 & 100.0 & Yes \\
\hline
\end{tabular}

TABLE 19: Normalized the decision matrix for different promotion contractors.

\begin{tabular}{|c|c|c|c|c|c|}
\hline \multirow{2}{*}{ Bidder } & \multicolumn{5}{|c|}{ Criteria } \\
\hline & $\mathrm{C} 1$ & $\mathrm{C} 2$ & $\mathrm{C} 3$ & $\mathrm{C} 4$ & $\mathrm{C} 5$ \\
\hline Bidder 1 & 0.000 & 1.000 & 0.000 & 0.000 & 0.667 \\
\hline Bidder 2 & 0.000 & 0.500 & 1.000 & 0.667 & 0.000 \\
\hline Bidder 3 & 1.000 & 0.000 & 0.400 & 1.000 & 1.000 \\
\hline
\end{tabular}

TABLE 20: Aggregated preference function for different promotion contractors.

\begin{tabular}{lccc}
\hline Bidder & Bidder 1 & Bidder 2 & Bidder 3 \\
\hline Bidder 1 & - & 0.192 & 0.250 \\
Bidder 2 & 0.283 & - & 0.215 \\
Bidder 3 & 0.593 & 0.467 & - \\
\hline
\end{tabular}

TABle 21: Entering, leaving, and net flows of different promotion contractors.

\begin{tabular}{lccc}
\hline Bidder & Entering flow & Leaving flow & Net outranking flow \\
\hline Bidder 1 & 0.438 & 0.221 & -0.218 \\
Bidder 2 & 0.329 & 0.249 & -0.080 \\
Bidder 3 & 0.233 & 0.530 & 0.298 \\
\hline
\end{tabular}

Table 22: Results of different calculation methods for Case Project 3.

\begin{tabular}{lccccc}
\hline \multirow{2}{*}{ Bidder } & \multicolumn{2}{c}{$\begin{array}{c}\text { Traditional weighted } \\
\text { arithmetic averaging method }\end{array}$} & \multicolumn{2}{c}{ DEA method } & \multicolumn{2}{c}{ The proposed method } \\
& Total score & Ranking & DEA value (\%) & Ranking & Net outranking flow \\
\hline Bidder 1 & 81.0 & 3 & 100.0 & 1 & -0.218 \\
Bidder 2 & 82.7 & 1 & 100.0 & 1 & -0.080 \\
Bidder 3 & 82.3 & 2 & 100.0 & 1 & 0.298 \\
\hline
\end{tabular}

From Table 22, the DEA values of bidders 1, 2, and 3 are $100 \%$, which illustrates the high repetition rate problem of the DEA method. Moreover, neither the traditional weighted arithmetic averaging method nor the DEA method can handle incomplete contractor selection process information. Therefore, the proposed method is more a general contractor selection technique and better suited for handling real-world problems. 


\section{Conclusions}

Contractor selection is a critical component of any company's pursuit of sustainable development, in addition, choosing suitable contractors ensures that project management plans are executed as expected. However, contractor selection includes qualitative and quantitative assessment criteria at the same time, which becomes a complicated MCDM problem. Traditional contractor selection methods are unable to handle nonexistent or missing assessment criteria data nor consider the relative importance of criteria in the contractor selection assessment process. In order to effectively address this problem, this study extended the PROMETHEE II method to propose a novel contractor selection technique. Moreover, three numerical examples are applied to prove the correctness and effectiveness of the proposed technique. The simulation results showed that the proposed extended PROMETHEE II approach is a more general contractor selection technique for handling incomplete information than the traditional weighted arithmetic averaging method and the DEA method.

The main advantages of the proposed extended PROMETHEE II approach are as follows:

(1) The proposed approach can handle incomplete assessment criteria information

(2) The proposed approach considers the relative importance of criteria

(3) The proposed approach considers the subjective preferences of experts

(4) The traditional weighted arithmetic average approach and DEA method can be viewed as special cases of the proposed approach

(5) The proposed approach provides a more flexible contractor selection technique to support contractor assessment for selection

This paper assumed that the experts have the same weight and did not consider the objective weight of the evaluation data. Further research studies can explore the simultaneous considerations of subjective and objective weights of assessment criteria to handle different field decision-making issues.

\section{Data Availability}

The contractor selection data used to support the findings of this study are included within the article.

\section{Conflicts of Interest}

The author declares that there are no conflicts of interest.

\section{Acknowledgments}

The authors would like to thank the Ministry of Science and Technology, Taiwan, for financially supporting this research under Contract Nos. MOST 109-2410-H-145-002 and MOST 110-2410-H-145-001.

\section{References}

[1] J. R. San Cristóbal, "Contractor selection using multicriteria decision-making methods," Journal of Construction Engineering and Management, vol. 138, no. 6, pp. 751-758, 2012.

[2] J. B. Yang, H. H. Wang, W. C. Wang, and S. M. Ma, "Using data envelopment analysis to support best-value contractor selection," Journal of Civil Engineering and Management, vol. 22, no. 2, pp. 199-209, 2015.

[3] C. Akcay, E. Manisali, and E. Manisalı, "Fuzzy decision support model for the selection of contractor in construction works," Revista de la construcción, vol. 17, no. 2, pp. 258-266, 2018.

[4] M. Hasnain, M. J. Thaheem, and F. Ullah, "Best value contractor selection in road construction projects: ANP-based decision support system," International Journal of Civil Engineering, vol. 16, no. 6A, pp. 695-714, 2018.

[5] K. H. Chang, "A novel supplier selection method that integrates the intuitionistic fuzzy weighted averaging method and a soft set with imprecise data," Annals of Operations Research, vol. 272, no. 1-2, pp. 139-157, 2019.

[6] G. Gharedaghi and M. Omidvari, "A pattern of contractor selection for oil and gas industries in a safety approach using ANP-DEMATEL in a Grey environment," International Journal of Occupational Safety and Ergonomics, vol. 25, no. 4, pp. 510-523, 2019.

[7] D. Molodtsov, "Soft set theory-first results," Computers \& Mathematics with Applications, vol. 37, no. 4-5, pp. 19-31, 1999.

[8] S. Danjuma, T. Herawan, M. A. Ismail, H. Chiroma, A. I. Abubakar, and A. M. Zeki, "A review on soft set-based parameter reduction and decision making," IEEE Access, vol. 5, pp. 4671-4689, 2017.

[9] K.-H. Chang, "A more general risk assessment methodology using a soft set-based ranking technique," Soft Computing, vol. 18, no. 1, pp. 169-183, 2014.

[10] B. Biswas, S. Bhattacharyya, A. Chakrabarti, K. N. Dey, J. Platos, and V. Snasel, "Colonoscopy contrast-enhanced by intuitionistic fuzzy soft sets for polyp cancer localization," Applied Soft Computing, vol. 95, Article ID 106492, 2020.

[11] K.-H. Chang, "A novel reliability allocation approach using the OWA tree and soft set," Annals of Operations Research, vol. 244, no. 1, pp. 3-22, 2016.

[12] Z. Tao, H. Chen, L. Zhou, and J. Liu, "2-Tuple linguistic soft set and its application to group decision making," Soft Computing, vol. 19, no. 5, pp. 1201-1213, 2015.

[13] F. Hao, Z. Pei, D.-S. Park, V. Phonexay, and H.-S. Seo, "Mobile cloud services recommendation: a soft set-based approach," Journal of Ambient Intelligence and Humanized Computing, vol. 9, no. 4, pp. 1235-1243, 2018.

[14] B. Paik and S. K. Mondal, "A distance-similarity method to solve fuzzy sets and fuzzy soft sets based decision-making problems," Soft Computing, vol. 24, no. 7, pp. 5217-5229, 2020.

[15] M. Abbas, M. Ali, and S. Romaguera, "Generalized operations in soft set theory via relaxed conditions on parameters," Filomat, vol. 31, no. 19, pp. 5955-5964, 2017.

[16] K.-H. Chang, "Enhanced assessment of a supplier selection problem by integration of soft sets and hesitant fuzzy linguistic term set," Proceedings of the Institution of Mechanical 
Engineers-Part B: Journal of Engineering Manufacture, vol. 229, no. 9, pp. 1635-1644, 2015.

[17] Z. Kong, J. Zhao, L. Wang, and J. Zhang, "A new data filling approach based on probability analysis in incomplete soft sets," Expert Systems with Applications, vol. 184, Article ID 115358, 2021.

[18] M. Akram, M. Shabir, A. Adeel, and A. N. Al-Kenani, "A multiattribute decision-making framework: VIKOR method with complex spherical fuzzy N-soft sets," Mathematical Problems in Engineering, vol. 2021, Article ID 1490807, 2021.

[19] T. C. Wen, K. H. Chang, and H. H. Lai, "Integrating the 2tuple linguistic representation and soft set to solve supplier selection problems with incomplete information," Engineering Applications of Artificial Intelligence, vol. 87, Article ID 103248, 2020.

[20] O. Dalkilic, "A novel approach to soft set theory in decisionmaking under uncertainty," International Journal of Computer Mathematics, vol. 98, no. 10, pp. 11935-11945, 2021.

[21] J. P. Brans and P. Vincke, "Note-A preference ranking organisation method," Management Science, vol. 31, no. 6, pp. 647-656, 1985.

[22] J. M. Brankovic, M. Markovic, and D. Nikolic, "Comparative study of hydraulic structures alternatives using promethee II complete ranking method," Water Resources Management, vol. 32, no. 10, pp. 3457-3471, 2018.

[23] X. J. Tian, X. D. Liu, and L. D. Wang, "An improved PROMETHEE II method based on axiomatic fuzzy sets," Neural Computing and Applications, vol. 25, no. 7-8, pp. 1675-1683, 2014.

[24] F. Samanlioglu and Z. Ayağ, "A fuzzy AHP-PROMETHEE II approach for evaluation of solar power plant location alternatives in Turkey," Journal of Intelligent \& Fuzzy Systems, vol. 33, no. 2, pp. 859-871, 2017.

[25] M. Rabbani, R. Heidari, and H. Farrokhi-Asl, "A bi-objective mixed-model assembly line sequencing problem considering customer satisfaction and customer buying behaviour," Engineering Optimization, vol. 50, no. 12, pp. 2123-2142, 2018.

[26] D. Jovanovic and D. Cvetkovic, "Multiple decision making criteria in the implementation of renewable energy sources," Tehnicki Vjesnik-Technical Gazette, vol. 25, no. 5, pp. 14921496, 2018.

[27] W. Zhang, C. Wang, L. Zhang et al., "Evaluation of the performance of distributed and centralized biomass technologies in rural China," Renewable Energy, vol. 125, pp. $445-455,2018$.

[28] D. F. D. Silva, J. C. S. Silva, L. G. O. Silva, L. Ferreira, and A. T. de Almeida, "Sovereign credit risk assessment with multiple criteria using an outranking method," Mathematical Problems in Engineering, vol. 2018, Article ID 8564764, 11 pages, 2018.

[29] A. d. S. Barbosa, R. A. Shayani, and M. A. G. d. Oliveira, "A multi-criteria decision analysis method for regulatory evaluation of electricity distribution service quality," Utilities Policy, vol. 53, pp. 38-48, 2018.

[30] G. Markovic, N. Zdravkovic, M. Karakasic, and M. Kolarevic, "Modified PROMETHEE approach for solving multi-criteria location problems with complex criteria functions," Tehnicki Vjesnik-Technical Gazette, vol. 27, no. 1, pp. 12-19, 2020.

[31] L. Z. Tong, Z. M. Pu, K. Chen, and J. J. Yi, "Sustainable maintenance supplier performance evaluation based on an extend fuzzy PROMETHEE II approach in petrochemical industry," Journal of Cleaner Production, vol. 273, Article ID 122771, 2020.
[32] R. Liu, Y. J. Zhu, Y. Chen, and H. C. Liu, "Occupational health and safety risk assessment using an integrated TODIMPROMETHEE model under linguistic spherical fuzzy environment," International Journal of Intelligent Systems, vol. 36, no. 11, pp. 6814-6836, 2021.

[33] W. Torbacki, "A hybrid MCDM model combining DANP and PROMETHEE II methods for the assessment of cybersecurity in industry 4.0," Sustainability, vol. 13, no. 16, p. 8833, 2021.

[34] M. S. Roodposhti, S. Rahimi, and M. J. Beglou, "PROMETHEE II and fuzzy AHP: an enhanced GIS-based landslide susceptibility mapping," Natural Hazards, vol. 73, no. 1, pp. 77-95, 2014.

[35] A. Kessili and S. Benmamar, "Prioritizing sewer rehabilitation projects using AHP-PROMETHEE II ranking method," Water Science and Technology, vol. 73, no. 2, pp. 283-291, 2016.

[36] S. R. Maity and S. Chakraborty, "Tool steel material selection using PROMETHEE II method," International Journal of Advanced Manufacturing Technology, vol. 78, no. 9-12, pp. 1537-1547, 2015.

[37] M. I. Ali, M. Shabir, and F. Feng, "Representation of graphs based on neighborhoods and soft sets," International Journal of Machine Learning and Cybernetics, vol. 8, no. 5, pp. 1525-1535, 2017.

[38] P. K. Maji, R. Biswas, and A. R. Roy, "Soft set theory," Computers and Mathematics with Applications, vol. 45, no. 45, pp. 555-562, 2003.

[39] K. H. Chang, Y. C. Chang, K. Chain, and H. Y. Chung, "Integrating soft set theory and fuzzy linguistic model to evaluate the performance of training simulation systems," PLoS One, vol. 11, no. 9, Article ID e0162092, 2016.

[40] Z. Xu, "A note on linguistic hybrid arithmetic averaging operator in multiple attribute group decision making with linguistic information," Group Decision and Negotiation, vol. 15 , no. 6 , pp. 593-604, 2006.

[41] J. M. Merigó, "A unified model between the weighted average and the induced OWA operator," Expert Systems with Applications, vol. 38, no. 9, pp. 11560-11572, 2011.

[42] K. H. Chang, "A general soft set and the OWA approach for a supplier selection problem under incomplete information," ICIC Express Letters, Part B: Applications, vol. 4, no. 2, pp. 395-400, 2013. 